\title{
Uji Pertumbuhan dan Produksi Tujuh Genotipe Bawang Putih (Allium sativum L.) di Dataran Rendah
}

\section{Growth and Production Testing on Seven Genotypes of Garlic (Allium sativum L.) in the Lowland}

\author{
Sayyidah Afridatul Ishthifaiyyah ${ }^{1}$, Sobir $^{1,2^{*}}$ \\ ${ }^{1}$ Departemen Agronomi dan Hortikultura, Fakultas Pertanian, Institut Pertanian Bogor (Bogor Agricultural University), \\ Jalan Meranti, Kampus IPB Darmaga, Bogor 16680, Indonesia. \\ ${ }^{2}$ Pusat Kajian Hortikultura Tropika, Lembaga Penelitian dan Pengabdian kepada Masyarakat Institut Pertanian Bogor, \\ Jl. Raya Pajajaran, Kampus IPB Baranangsiang, Bogor, Indonesia
}

Diterima 15 Agustus 2018/Disetujui 22 Oktober 2018

\begin{abstract}
Garlic consumption in Indonesia increases since 2013, but the production is still low because the productivity and land availability are also low. Garlic needs low temperature and long photoperiods to produce bulb. This research aims to study the growth and production of seven genotypes of garlic in the lowland. The research was conducted in experimental field of PKHT Pasir Kuda, PKHT IPB. The experimental design is Randomized Complete Block Design one factor, that was genotype with 3 replications. The plant materials were two local genotypes of garlic, those were Sangga Sembalun (BP-01) and Lumbu Hijau (BP-02), and also five Chinese genotypes of garlic (BP-25, BP-33, BP-35, BP-60, and BP-100). Chinese genotypes exclude BP-25 have better vegetative growth than local genotypes. The vegetative growth of local genotypes showed unsignificant except on the number of leaves. BP-01 had more leaves than BP-02. Both local and Chinese genotypes showed unsignificant difference in bulb weight per plot. BP-60 has the least cloves number than the other genotypes. Both Chinese genotypes (BP-25 and BP-60) have higher means of cloves dried weight and cloves length than local genotypes. BP$01, B P-02, B P-25$, and BP-60 were the potential genotypes that can be developed in the lowland.
\end{abstract}

Keywords: bulbing, Chinese garlic, local garlic, photoperiod

\section{ABSTRAK}

Konsumsi bawang putih di Indonesia mengalami peningkatan sejak tahun 2013, tetapi produksinya masih rendah karena rendahnya produktivitas dan ketersediaan lahan yang sesuai. Bawang putih memerlukan suhu dan panjang hari yang tepat untuk mendukung proses pengumbian. Penelitian ini bertujuan untuk mempelajari pertumbuhan dan produksi tujuh genotipe bawang putih di dataran rendah. Penelitian dilaksanakan di Kebun Percobaan PKHT Pasir Kuda, Bogor. Rancangan percobaan yang digunakan adalah Rancangan Kelompok Lengkap Teracak (RKLT) satu faktor berupa genotipe dengan 3 ulangan. Bahan tanaman yang digunakan terdiri atas dua genotipe bawang putih lokal yaitu Sangga Sembalun (BP-01) dan Lumbu Hijau (BP-02) serta lima genotipe bawang putih introduksi dari Cina (BP-25, BP-33, BP-35, BP-60, dan BP-100). Bawang putih Cina selain BP-25 mempunyai pertumbuhan vegetatif yang lebih baik dibandingkan bawang putih lokal. Pertumbuhan vegetatif kedua genotipe lokal tidak memiliki perbedaan yang signifikan kecuali pada karakter jumlah daun. Jumlah daun BP-01 lebih banyak daripada BP-02. Baik genotipe lokal maupun Cina mempunyai bobot per plot yang tidak berbeda nyata. BP-60 mempunyai jumlah siung yang paling sedikit di antara genotipe lain. BP-25 dan BP-60 mempunyai nilai tengah bobot kering siung per umbi dan panjang siung yang lebih tinggi dibandingkan genotipe bawang putih lokal. BP-01, BP-02, BP-25, dan BP-60 berpotensi dikembangkan di dataran rendah.

Kata kunci: bawang putih Cina, bawang putih lokal, panjang hari, pengumbian

\section{PENDAHULUAN}

Bawang putih (Allium sativum L.) merupakan komoditas sayuran yang penting bagi masyarakat Indonesia. Konsumsi per kapita bawang putih di Indonesia tahun 2016

\footnotetext{
* Penulis untuk korespondensi. e-mail: ridwanisobir@gmail.com
}

mencapai $1.767 \mathrm{~kg}$ (BPS, 2016). Produksi bawang putih dalam negeri pada tahun yang sama mencapai 21,151 ton (BPS, 2016). Produksi tersebut belum memenuhi kebutuhan bawang putih dalam negeri sehingga pemerintah menerapkan kebijakan impor bawang putih sebesar 356,913.608 ton atau senilai 405,995,933 US\$ selama bulan Januari hingga September 2017 (Kementan, 2017). 
Bawang putih di Indonesia sebagian besar diimpor dari Cina. Produksi bawang putih di Cina pada tahun 2014 mencapai 19,984,724 ton. Tingginya produksi tersebut salah satunya didukung oleh luas panen untuk pertanaman bawang putih yang mencapai 785,452 ha (FAO, 2017). Luasan tersebut jauh lebih besar dibandingkan luas panen di Indonesia yakni 1,913 ha pada tahun yang sama. Luas panen bawang putih di Indonesia mengalami peningkatan menjadi 2,407 ha pada tahun 2016. Meski demikian, luas panen tersebut turun sebesar $6.09 \%$ dibandingkan tahun 2015 (BPS dan Ditjen Horti, 2017).

Luas panen yang rendah di Indonesia disebabkan oleh keterbatasan lahan yang sesuai untuk pertanaman bawang putih. Bawang putih di Indonesia umumnya ditanam di dataran tinggi karena bawang putih memerlukan suhu rendah dan panjang hari yang tepat dalam proses pertumbuhannya. Rubatzky dan Yamaguchi (1998) menjelaskan bahwa suhu rendah pada pertanaman bawang putih diperlukan agar tanaman mendapatkan vernalisasi untuk menginisiasi pembentukan umbi. Interaksi suhu dengan panjang hari berpengaruhterhadap pembesaranumbi.Pemaparanterhadap suhu rendah yang berkepanjangan dapat memperpendek panjang hari yang diperlukan. Penanaman bawang putih di dataran tinggi terbatas karena penggunaan lahan bersaing dengan kebutuhan konservasi dan pertanaman sayuran dataran tinggi lain seperti kubis-kubisan, kentang, dan wortel.

Faktor lain yang menyebabkan rendahnya produksi bawang putih dalam negeri yakni produktivitas. Produktivitas bawang putih di Indonesia pada tahun 2016 hanya sebesar 8.79 ton ha-1 (BPS dan Ditjen Horti, 2017). Sebaliknya, produktivitas bawang putih Cina pada tahun 2014 mencapai 25.44 ton ha-1 (FAO, 2017). Bawang putih Cina lebih disukai konsumen dibandingkan bawang putih lokal karena mempunyai produktivitas yang tinggi, mempunyai kualitas yang baik dan harga yang terjangkau (Hardiyanto et al., 2007). Introduksi bawang putih dari Cina diperlukan untuk memperoleh varietas unggul bawang putih yang cocok ditanam di dataran rendah. Penelitian mengenai penanaman bawang putih asal Cina di dataran rendah perlu dilakukan untuk mempelajari pertumbuhan dan produksinya di Indonesia sebagai upaya untuk mewujudkan swasembada bawang putih.

\section{BAHAN DAN METODE}

Percobaan dilaksanakan di Kebun Percobaan Pusat Kajian Hortikultura Tropika IPB Pasir Kuda, Bogor, Jawa Barat dengan ketinggian tempat $262 \mathrm{~m}$ dpl. Pengamatan pasca panen dilakukan di Laboratorium Pemuliaan Tanaman, Departemen Agronomi dan Hortikultura, Institut Pertanian Bogor. Percobaan dilaksanakan pada bulan September 2017 hingga Februari 2018.

Bahan tanaman yang digunakan adalah 2 genotipe bawang putih lokal berupa Sangga Sembalun (BP-01) dan Lumbu Hijau (BP-02) serta 5 genotipe bawang putih introduksi dari Cina (BP-25, BP-33, BP-35, BP-60, BP100). Huruf BP pada kode genotipe merupakan singkatan dari Bawang Putih, sedangkan dua angka di belakang huruf pada bawang putih introduksi menunjukkan harga bawang putih per kilogram dalam ribuan. Genotipe BP-01, BP02, dan BP-25 merupakan bawang putih tipe hardneck, sedangkan BP-33, BP-35, BP-60, dan BP-100 merupakan bawang putih tipe softneck. Bahan lain yang digunakan adalah pupuk, asam humat, kapur pertanian, pestisida, polynet, bambu, dan label. Alat yang digunakan yaitu alat tanam, alat tulis, termometer, lemari es, penggaris, meteran, timbangan, dan jangka sorong.

Percobaan dilakukan menggunakan Rancangan Kelompok Lengkap Teracak (RKLT) satu faktor yaitu genotipe (7 genotipe) dengan tiga ulangan sehingga dihasilkan 21 satuan percobaan. Setiap satuan percobaan terdiri dari 50 tanaman sehingga jumlah tanaman seluruh satuan percobaan sebanyak 1,050 tanaman. Data yang diperoleh selanjutnya diolah menggunakan uji $\mathrm{F}$ pada taraf 5\%. Apabila perlakuan berpengaruh nyata, dilakukan uji lanjut Beda Nyata Jujur (BNJ) menggunakan aplikasi SAS.

Prosedur percobaan yang dilaksanakan meliputi vernalisasi, persiapan lahan, penanaman, pemupukan, pemeliharaan, dan pemanenan. Vernalisasi merupakan penyimpanan bahan tanam (umbi bawang putih) pada suhu rendah. Umbi bawang putih disimpan di dalam lemari pendingin dengan suhu $5{ }^{\circ} \mathrm{C}-7{ }^{\circ} \mathrm{C}$ selama 30 hari. Rubatzky dan Yamaguchi (1998) menjelaskan bahwa penyimpanan umbi pada suhu rendah sangat penting khususnya untuk tanaman yang ditanam di daerah dengan suhu di atas $10{ }^{\circ} \mathrm{C}$ di mana tidak ada suhu rendah di lapangan yang diperlukan untuk pembentukan umbi.

Umbi bawang putih dapat berkembang dengan baik pada tanah ringan bertekstur lempung berpasir dan mempunyai porositas yang baik (Hilman et al., 1997). Pengolahan lahan dilakukan satu minggu sebelum tanam secara manual. Lahan diberi pupuk kandang dan kapur dengan dosis masing-masing 10 ton $\mathrm{ha}^{-1}$ dan 1 ton $\mathrm{ha}^{-1}$, serta asam humat dan fungisida dengan konsentrasi masingmasing $2 \mathrm{~g} \mathrm{l}^{-1}$ dan $1 \mathrm{~g} \mathrm{l}^{-1}$. Lahan kemudian dibuat bedengan dengan ukuran $7 \mathrm{~m}$ x $1 \mathrm{~m}$. Kriteria umbi yang baik untuk dijadikan bibit antara lain bebas dari hama dan penyakit, bobot per siung $1.5 \mathrm{~g}-3.0 \mathrm{~g}$, siung bernas, dan pangkal batang berisi penuh dan keras (Hilman et al., 1997). Bibit ditanam dengan kedalaman $2 \mathrm{~cm}-3 \mathrm{~cm}$. Jarak tanam yang digunakan adalah $15 \mathrm{~cm} \times 10 \mathrm{~cm}$.

Pupuk yang diberikan pada pertanaman bawang putih yakni pupuk organik dan anorganik. Pupuk organik berupa pupuk kandang kambing diaplikasikan saat persiapan lahan. Pupuk anorganik diberikan secara berkala dengan dosis 225 $\mathrm{kg} \mathrm{ha}^{-1} \mathrm{NPK}, 250 \mathrm{~kg} \mathrm{ha}^{-1}$ urea, $200 \mathrm{~kg} \mathrm{ha}^{-1} \mathrm{SP}-36,150 \mathrm{~kg}$ $\mathrm{ha}^{-1} \mathrm{KCl}, 250 \mathrm{~kg} \mathrm{ha}^{-1} \mathrm{ZA}$, dan $175 \mathrm{~kg} \mathrm{ha}^{-1} \mathrm{~K}_{2} \mathrm{SO}_{4}$. Unsur hara mikro $\mathrm{B}$ diberikan dengan dosis sesuai anjuran yang tertera pada kemasan. Aplikasi pupuk dilaksanakan pada saat tanam, 14 HST, 35 HST, 56 HST, dan 70 HST.

Mulsa yang digunakan adalah mulsa alami yang berasal dari jerami kering. Penggunaan mulsa plastik tidak dianjurkan karena dapat meningkatkan suhu tanah di sekitar pertanaman dan menghambat pertumbuhan dan perkembangan tanaman (Setiawati et al., 2007). Mulsa 
diaplikasikan pada pertanaman bawang putih dengan ketebalan sekitar $2 \mathrm{~cm}$. Pemulsaan pada musim hujan dilakukan untuk menghindari percikan tanah ke daun sehingga daun terhindar dari serangan hama dan penyakit.

Pemeliharaan yang dilakukan antara lain pengairan, pengendalian gulma, serta pengendalian hama dan penyakit tanaman. Pengairan dilakukan dengan penyiraman secara manual sesuai kebutuhan. Pengairan dihentikan 10 hari menjelang panen. Pengendalian gulma dilakukan secara manual. Pengendalian hama dan penyakit tanaman dilakukan secara manual dan kimiawi menggunakan pestisida sesuai dengan kondisi di lapang. Panen bawang putih dilakukan pada 118 HST. Beberapa genotipe bawang putih dipanen lebih awal, yakni pada 63 HST, 77 HST, dan 91 HST. Umur panen bawang putih menurut Setiawati et al. (2007) adalah 90 - 120 HST. Ciri-ciri tanaman yang siap dipanen yaitu warna daun menguning dengan tingkat kelayuan 35\%-60\%. Panen dilakukan dengan mencabut tanaman menggunakan tangan saat cuaca cerah.

Pengamatan dilakukan terhadap 10 tanaman contoh yang dipilih secara acak pada setiap satuan percobaan. Peubah yang diamati yakni karakter kualitatif dan karakter kuantitatif berupa pertumbuhan vegetatif dan komponen hasil. Pengamatan karakter kualitatif mengacu pada pedoman pengujian kebaruan, keseragaman, dan kestabilan bawang putih dari International Union for The Protection of New Varieties of Plants (UPOV). Karakter vegetatif yang diamati meliputi tinggi tanaman, panjang daun, lebar daun, jumlah daun, dan diameter batang semu serta persentase panjang tunas dan persentase tumbuh tanaman. Pengamatan komponen hasil meliputi persentase pengumbian, bobot basah umbi per tanaman, bobot kering umbi per tanaman, bobot kering umbi per plot, diameter umbi per tanaman, panjang umbi per tanaman, jumlah siung per umbi, rata-rata bobot kering siung per umbi, rata-rata lebar siung, dan ratarata panjang siung.

\section{HASIL DAN PEMBAHASAN}

\section{Kondisi Umum}

Penelitian dilaksanakan pada bulan September 2017 hingga Februari 2018. Vernalisasi dilakukan di Departemen Agronomi dan Hortikultura IPB selama 30 hari sejak bulan September hingga Oktober 2017. Umbi yang telah divernalisasi ditanam di Kebun Percobaan Pusat Kajian Hortikultura Tropika Pasir Kuda, Bogor dengan ketinggian tempat $262 \mathrm{~m}$ dpl. Bawang putih di Indonesia umumnya ditanam di daerah dengan ketinggian lebih dari $700 \mathrm{~m} \mathrm{dpl}$ (Hilman et al., 1997).

Jumlah curah hujan selama pelaksanaan penelitian yaitu 1,861.5 mm dengan hari hujan sebanyak 82 hari. Rata-rata suhu minimum dan maksimum berkisar antara 22 ${ }^{0} \mathrm{C}$ hingga $32{ }^{\circ} \mathrm{C}$ dengan rata-rata suhu harian $26{ }^{\circ} \mathrm{C}$. Lama penyinaran matahari maksimum dan minimum yaitu 0 jam dan 12 jam dengan rata-rata sebesar 6.12 jam. Rata-rata intensitas cahaya sebesar $473.90 \mathrm{Cal}\left(\mathrm{cm}^{2}\right)^{-1}$ dan rata-rata kelembaban relatif sebesar $81.54 \%$ (BMKG, 2018).
Organisme pengganggu tanaman yang muncul selama penelitian antara lain nematoda Ditylenchus dipsaci dan cendawan Alternaria porri. Serangan nematoda menyebabkan tanaman gagal berumbi bahkan mati. Jenking dan Jain (2010) dan Brewster (2008) menjelaskan bahwa nematoda menyebabkan umbi muda menjadi bengkak dan lunak. Daun tanaman yang terserang nematoda membelit dan kerdil. Nematoda mampu menyekresikan enzim yang dapat menghilangkan pektin dalam tanaman sehingga jaringan tanaman melunak karena sel-selnya terpisah. Kondisi tersebut mempermudah nematoda untuk menyebar dalam jaringan tanaman dan menyebabkan tanaman mudah terserang busuk bakteri. Nematoda juga mengeluarkan zat pengatur tumbuh tanaman yang dapat menonaktifkan auksin serta menyebabkan pembelahan dan pembesaran sel yang tidak normal. Ditylenchus dipsaci dapat bertahan hidup dan menyebar pada tanah yang lembab.

Pengendalian Ditylenchus dipsaci dilakukan dengan menggunakan bahan tanaman dan media tanam yang bebas dari nematoda. Walker (1957) menjelaskan bahwa perendaman benih yang terinfeksi dalam air bersuhu 43 ${ }^{0} \mathrm{C}$ hingga $44{ }^{\circ} \mathrm{C}$ selama 3 jam juga dapat dilakukan untuk mencegah penyebaran nematoda. Pengendalian di lapang dapat dilakukan dengan fumigasi tanah menggunakan ethyl dibromide (EDB) atau 1.3 dichloropropene-1.2 dichloropropane (DD). Pengaturan drainase pun perlu diterapkan dengan baik untuk mencegah penyebaran nematoda melalui aliran air.

Brewster (2008) menjelaskan gejala tanaman yang terserang Alternaria porri antara lain adanya luka berair yang memanjang pada daun dan tangkai bunga dengan bagian tengah luka berwarna ungu atau cokelat. Alternaria porri juga dapat menyebabkan umbi bawang putih menjadi busuk. Organisme tersebut mampu menghasilkan spora pada lingkungan dengan kelembaban relatif lebih dari $90 \%$ dan suhu optimal $25{ }^{\circ} \mathrm{C}$. Spora mampu menginfeksi tanaman saat daun dalam kondisi basah setidaknya selama 6 jam. Pengendalian Alternaria porri dapat dilakukan melalui

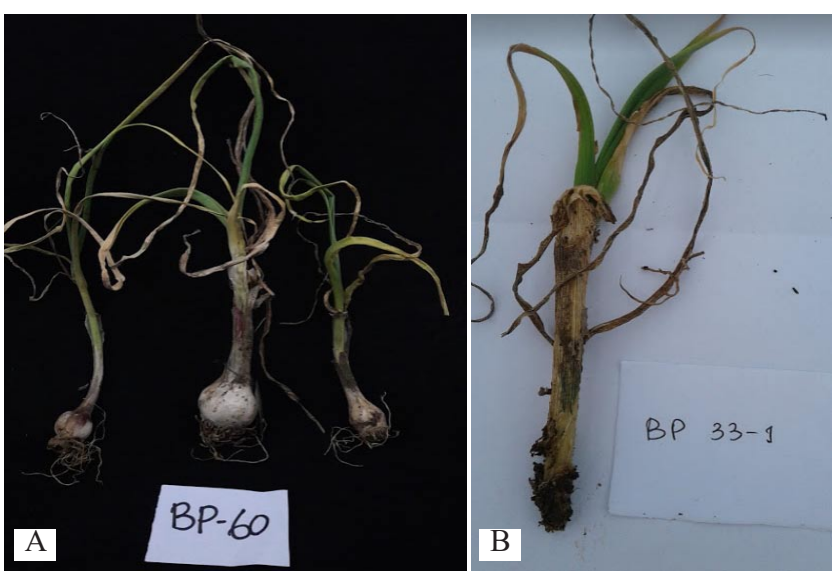

Gambar 1. Gejala tanaman yang terserang penyakit; (a) Tanaman bawang putih yang terserang nematoda Ditylenchus dipsaci, (b) Tanaman bawang putih yang terserang cendawan Alternaria porri 
praktik sanitasi lahan dan rotasi tanaman. Pengaturan jarak tanam juga perlu diperhatikan untuk mengurangi kelembaban daun.

\section{Karakter Kualitatif}

Karakter kualitatif diamati pada tujuh genotipe bawang putih yang diuji. Bagian tanaman yang diamati meliputi daun, batang semu, tangkai bunga, dan umbi. Penentuan karakter kualitatif pada penelitian ini mengikuti pedoman dari UPOV (2001).

\section{Karakter kualitatif pada daun, batang semu, dan tangkai bunga}

Karakter yang diamati meliputi pola kelengkungan daun, warna hijau daun, keberadaaan tangkai bunga pada batang semu, kelengkungan tangkai bunga, dan keberadaan bulbil pada tangkai bunga. Dua genotipe bawang putih lokal menunjukkan pola kelengkungan daun erect atau tegak, sedangkan genotipe introduksi dari Cina kecuali BP-25 mempunyai pola kelengkungan semi-erect.

Warna daun BP-01, BP-02, dan BP-25 yakni hijau gelap, sedangkan daun tanaman genotipe lain berwarna hijau terang. Tangkai bunga hanya ditemukan pada genotipe BP-01 dengan bentuk tangkai bunga melengkung. Kedua genotipe lokal mempunyai bulbil (Gambar 2), sedangkan kelima genotipe introduksi tidak. Brewster (2008) menyatakan bahwa pembentukan bulbil merupakan penyimpangan dari proses pembungaan. Pembungaan yang abnormal dapat terjadi akibat tanaman mendapatkan penyinaran matahari selama 8-10 jam.

\section{Karakter kualitatif pada umbi}

Tujuh genotipe bawang putih yang diuji secara umum mempunyai bentuk umbi yang circular. Letak siung pada ujung umbi bawang genotipe lokal yakni inserted, sedangkan genotipe introduksi dari Cina mempunyai letak siung yang setara (at same level) dengan ujung umbi kecuali BP-25. Dasar umbi genotipe bawang putih yang diuji secara umum berbentuk rounded, kecuali BP-33 dan BP 60 yang mempunyai bentuk dasar umbi flat atau datar. Siung eksternal hanya terbentuk pada genotipe BP-01. Kedua genotipe lokal mempunyai kulit umbi yang tipis, sedangkan genotipe introduksi mempunyai kulit umbi dengan ketebalan yang medium kecuali BP-25 yang mempunyai kulit umbi lebih tebal.

\section{Karakter Kuantitatif}

\section{Rekapitulasi Sidik Ragam}

Analisis ragam dilakukan untuk mengetahui pengaruh perlakuan terhadap karakter yang diamati. Hasil uji sidik ragam menunjukkan bahwa perlakuan genotipe berpengaruh nyata pada taraf $1 \%$ terhadap semua karakter vegetatif tanaman dan beberapa karakter komponen hasil seperti persentase pengumbian, bobot kering siung per umbi, panjang siung, dan lebar siung (Tabel 3). Genotipe tidak berpengaruh nyata terhadap komponen hasil yang lain, kecuali jumlah siung.

Pengelompokkan berpengaruh nyata pada taraf 5\% terhadap karakter panjang daun, bobot kering siung per



Gambar 2. Bulblet pada tanaman bawang putih; (a) bulblet tanaman BP-02, (b) bulblet tanaman BP-01

Tabel 1. Karakter kualitatif daun, batang semu, dan tangkai bunga tujuh genotipe bawang putih

\begin{tabular}{lccccc}
\hline \multirow{2}{*}{ Genotipe } & Foliage & Daun & \multicolumn{2}{c}{ Batang semu } & \multicolumn{2}{c}{ Tangkai bunga } \\
\cline { 2 - 5 } & Pola kelengkungan & Warna hijau & Tangkai bunga & Kelengkungan & Bulblets \\
\hline BP-01 & Tegak & Gelap & Ada & Ada & Ada \\
BP-02 & Tegak & Gelap & Tidak ada & Tidak ada & Ada \\
BP-25 & Tegak & Gelap & Tidak ada & Tidak ada & Tidak ada \\
BP-33 & Semi tegak & Terang & Tidak ada & Tidak ada & Tidak ada \\
BP-35 & Semi tegak & Terang & Tidak ada & Tidak ada & Tidak ada \\
BP-60 & Semi tegak & Terang & Tidak ada & Tidak ada & Tidak ada \\
BP-100 & Semi tegak & Terang & Tidak ada & Tidak ada & Tidak ada \\
\hline
\end{tabular}


umbi, dan panjang siung, tetapi tidak berpengaruh nyata terhadap karakter lain yang diujikan. Hasil uji F tersebut menunjukkan bahwa lingkungan tumbuh tanaman bersifat homogen sehingga pengelompokkan tidak berpengaruh signifikan terhadap pertumbuhan tanaman.

Persentase tumbuh tanaman mempunyai nilai koefisien keragaman (KK) terendah yakni sebesar $4.74 \%$, sedangkan persentase pengumbian mempunyai nilai KK tertinggi yakni $31.47 \%$. Sari et al. (2014) menjelaskan bahwa koefisien keragaman dikelompokkan menjadi beberapa kategori yaitu rendah (0\%-25\%), agak rendah (25\%-50\%), cukup tinggi (50\%-75\%), dan tinggi (75\%-100\%). Nilai koefisien keragaman rendah menunjukkan bahwa suatu genotipe mempunyai keragaman yang sempit pada karakter tertentu. Keragaman yang sempit diperlukan pada genotipe yang akan dilepas menjadi varietas karena sempitnya keragaman menunjukkan bahwa penampilan genotipe tersebut seragam. Sebaliknya, nilai koefisien keragaman yang tinggi diperlukan dalam pembentukan populasi dasar agar proses seleksi dapat berjalan efektif.

Tabel 2. Karakter kualitatif umbi tujuh genotipe bawang putih

\begin{tabular}{lccccc}
\hline Genotipe & Bentuk umbi & $\begin{array}{c}\text { Posisi siung pada } \\
\text { ujung umbi }\end{array}$ & Bentuk dasar umbi & Siung eksternal & $\begin{array}{c}\text { Ketebalan kulit } \\
\text { umbi }\end{array}$ \\
\hline BP-01 & Circular & Inserted & Rounded & Ada & Tipis \\
BP-02 & Circular & Inserted & Rounded & Tidak ada & Tipis \\
BP-25 & Circular & Exerted & Rounded & Tidak ada & Tebal \\
BP-33 & Circular & At same level & Flat & Tidak ada & Medium \\
BP-35 & Circular & At same level & Rounded & Tidak ada & Medium \\
BP-60 & Circular & At same level & Flat & Tidak ada & Medium \\
BP-100 & Circular & At same level & Rounded & Tidak ada & Medium \\
\hline
\end{tabular}

Tabel 3. Rekapitulasi sidik ragam pada karakter kuantitatif tujuh genotipe bawang putih

\begin{tabular}{|c|c|c|c|}
\hline Karakter & F hitung genotipe & F hitung ulangan & Koefisien Keragaman (\%) \\
\hline \multicolumn{4}{|c|}{ Vegetatif } \\
\hline Persentase panjang tunas (\%) & $26.07^{* *}$ & $0.98^{\text {tn }}$ & 19.82 \\
\hline Persentase tumbuh tanaman (\%) & $76.21^{* *}$ & $2.28^{\text {tn }}$ & 4.74 \\
\hline Tinggi tanaman $(\mathrm{cm})$ & $18.05^{* *}$ & $3.82^{\text {tn }}$ & 17.38 \\
\hline Panjang daun $(\mathrm{cm})$ & $23.09^{* *}$ & $4.33^{*}$ & 16.23 \\
\hline Lebar daun $(\mathrm{cm})$ & $38.50^{* *}$ & $1.27^{\mathrm{tn}}$ & 10.93 \\
\hline Jumlah daun & $27.09^{* *}$ & $2.91^{\text {tn }}$ & 12.21 \\
\hline Diameter batang semu (mm) & $55.31^{* *}$ & $2.41^{\text {tn }}$ & 9.68 \\
\hline \multicolumn{4}{|c|}{ Komponen hasil } \\
\hline $\begin{array}{l}\text { Persentase pengumbian (\%) } \\
\text { ( }\end{array}$ & $9.52^{* *}$ & $0.12^{\text {tn }}$ & $31.47^{\mathrm{t}}$ \\
\hline Bobot basah umbi per tanaman (g) & $3.28^{\mathrm{tn}}$ & $0.54^{\text {tn }}$ & $15.42^{\mathrm{t}}$ \\
\hline Bobot kering umbi per tanaman $(\mathrm{g})$ & $3.38^{\mathrm{tn}}$ & $0.49^{\text {tn }}$ & $15.87^{\mathrm{t}}$ \\
\hline Bobot kering umbi per plot (g) & $0.65^{\text {tn }}$ & $0.18^{\text {th }}$ & $20.99^{t}$ \\
\hline Diameter umbi $(\mathrm{cm})$ & $2.91^{\text {tn }}$ & $0.24^{\text {th }}$ & 21.19 \\
\hline Panjang umbi (cm) & $3.87^{\mathrm{tn}}$ & $0.73^{\text {th }}$ & 16.39 \\
\hline Jumlah siung & $7.37^{*}$ & $1.50^{\text {th }}$ & 22.63 \\
\hline Bobot kering siung per umbi (g) & $22.40^{* *}$ & $6.90^{*}$ & 24.37 \\
\hline Lebar siung $(\mathrm{cm})$ & $15.97^{* *}$ & $2.59^{\mathrm{tn}}$ & 12.72 \\
\hline Panjang siung $(\mathrm{cm})$ & $27.81^{* *}$ & $7.49^{*}$ & 9.84 \\
\hline
\end{tabular}

Keterangan: *: berpengaruh nyata pada taraf $\alpha=5 \%,{ }^{* *}$ : berpengaruh nyata pada taraf $\alpha=1 \%$, tn: tidak berpengaruh nyata, $:$ hasil dari transformasi data 
Persentase Panjang Tunas, Tumbuh Tanaman, dan Pengumbian

Pertumbuhan tunas diamati setelah umbi bawang putih divernalisasi selama 30 hari. Tiga umbi dari setiap genotipe diambil secara acak kemudian dipotong membujur untuk melihat persentase panjang tunas yang muncul dari basal plate (Gambar 3). Hasil uji lanjut Beda Nyata Jujur (BNJ) menunjukkan bahwa genotipe bawang putih introduksi mempunyai persentase panjang tunas yang lebih tinggi dibandingkan genotipe lokal. Kelima genotipe bawang putih introduksi mempunyai persentase panjang tunas lebih dari $75 \%$, sedangkan bawang putih lokal hanya mencapai $6.7 \%$ dan $13.33 \%$ (Tabel 4 ).

Persentase tumbuh tanaman diamati pada hari ke20 setelah tanam. Hasil pengujian menunjukkan bahwa persentase tumbuh genotipe BP-33 tidak berbeda nyata dengan BP-35, BP-60, dan BP-100. Keempat genotipe tersebut mempunyai persentase tumbuh yang lebih tinggi dibandingkan BP-25, BP-01, dan BP-02. Genotipe yang mempunyai persentase tumbuh terendah adalah BP-02 sebesar 45.3\%. BP-02 merupakan bawang putih lokal varietas Lumbu Hijau. Menurut deskripsi varietas tanaman dari Kementerian Pertanian (1984), Lumbu Hijau baik ditanam pada daerah dengan ketinggian 900-1,100 m dpl. Rendahnya persentase tumbuh tanaman BP-02 kemungkinan disebabkan oleh lingkungan tumbuh yang tidak sesuai.

Setiap genotipe menunjukan perbedaan dalam kemampuan berumbi. Persentase pengumbian menunjukkan banyaknya tanaman yang mampu berumbi dalam setiap petak percobaan. Bawang putih lokal mempunyai persentase pengumbian yang lebih besar daripada bawang putih introduksi selain BP-25 dan BP-60. Genotipe bawang putih dengan persentase pengumbian terbesar adalah BP-02 sebesar $24 \%$, tetapi nilai tersebut tidak berbeda nyata dengan BP-01, BP-25, dan BP-60. Genotipe BP-25 mempunyai persentase pengumbian yang tertinggi di antara genotipe bawang putih introduksi lainnya yakni sebesar $14.7 \%$. Nilai tersebut tidak berbeda nyata dengan persentase pengumbian genotipe bawang putih introduksi yang lain. Genotipe BP35, BP-100 dan BP-33 menunjukan persentase pengumbian yang tidak berbeda nyata yaitu mencapai $0.7 \%$ dan $2.0 \%$.

Tabel 4. Nilai tengah persentase panjang tunas, persentase tumbuh tanaman, dan persentase pengumbian tujuh genotipe bawang putih

\begin{tabular}{cccc}
\hline Genotipe & Persentase panjang tunas (\%) & Persentase tumbuh tanaman (\%) & Persentase pengumbian (\%) $^{\mathrm{t}}$ \\
\hline BP-01 & $6.7 \mathrm{~b}$ & $72.7 \mathrm{~b}$ & $22.0 \mathrm{a}$ \\
BP-02 & $13.3 \mathrm{~b}$ & $45.3 \mathrm{c}$ & $24.0 \mathrm{a}$ \\
BP-25 & $96.7 \mathrm{a}$ & $81.3 \mathrm{~b}$ & $14.7 \mathrm{ab}$ \\
BP-33 & $83.3 \mathrm{a}$ & $99.3 \mathrm{a}$ & $2.0 \mathrm{~b}$ \\
BP-35 & $81.7 \mathrm{a}$ & $98.7 \mathrm{a}$ & $0.7 \mathrm{~b}$ \\
BP-60 & $81.7 \mathrm{a}$ & $96.7 \mathrm{a}$ & $6.0 \mathrm{ab}$ \\
BP-100 & $75.0 \mathrm{a}$ & $98.7 \mathrm{a}$ & $0.7 \mathrm{~b}$ \\
\hline
\end{tabular}

Keterangan: $\quad$ t: Transformasi data $=$ SQRT $(x+1)$. Angka-angka yang diikuti huruf yang sama pada kolom yang sama menunjukkan tidak berbeda nyata berdasarkan uji lanjut Beda Nyata Jujur (BNJ) pada taraf $\alpha=5 \%$



BP-01

BP-02

BP-25

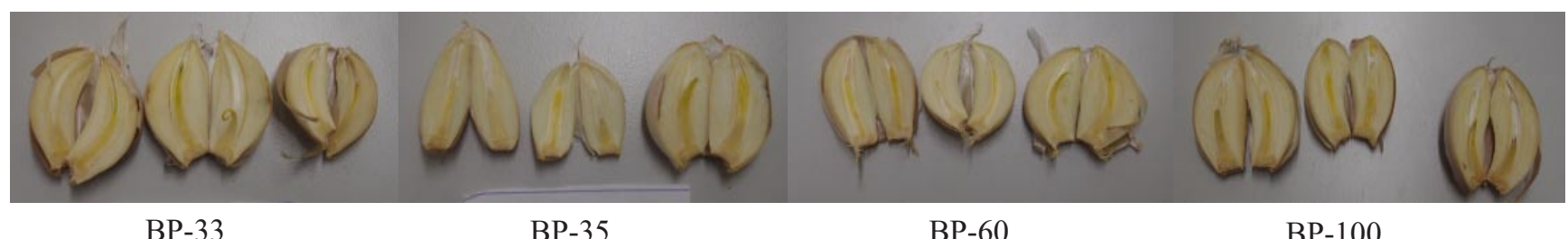

BP-33

BP-35

BP-60

BP-100

Gambar 3. Pertumbuhan tunas tujuh genotipe bawang putih 


\section{Karakter Vegetatif}

Hasil uji lanjut menunjukkan bahwa bawang putih introduksi mempunyai pertumbuhan vegetatif yang lebih baik daripada bawang putih lokal. Kelima genotipe bawang putih introduksi mempunyai nilai tengah tinggi tanaman, panjang daun, lebar daun, jumlah daun, dan diameter batang semu yang lebih besar dibandingkan dua genotipe bawang putih lokal (Tabel 5). Meski demikian, tidak terdapat perbedaan yang signifikan antara karakter vegetatif BP-25 dengan BP-01. BP-25 merupakan genotipe bawang putih introduksi yang mempunyai pertumbuhan terendah dilihat dari nilai tengah lebar daun dan diameter batang semu. Genotipe bawang putih yang mempunyai pertumbuhan vegetatif terendah adalah BP-02. Tetapi, nilai tengah karakter vegetatif BP-02 tidak berbeda nyata dengan BP-01 kecuali jumlah daun.

Perbedaan pertumbuhan genotipe bawang putih yang diuji kemungkinan disebabkan oleh ukuran bahan tanaman yang berbeda. Umbi bawang putih genotipe BP-01, BP02, dan BP-25 mempunyai ukuran yang relatif lebih kecil dibandingkan keempat genotipe lainnya. Umbi yang kecil menandakan jumlah cadangan makanan yang dimiliki genotipe tersebut sedikit sehingga tidak cukup untuk ditransformasikan menjadi organ tubuh tanaman.

\section{Komponen Hasil}

Pengujian terhadap komponen hasil hanya dilakukan pada empat genotipe bawang putih, yaitu BP-01, BP-02, BP-25, dan BP-60. Ketiga genotipe lain tidak diuji karena genotipe tersebut tidak menghasilkan umbi pada ulangan tertentu. Keempat genotipe bawang putih yang diuji tidak menunjukkan perbedaan yang signifikan pada beberapa karakter komponen hasil, seperti bobot basah umbi per tanaman, bobot kering umbi per tanaman, bobot kering umbi per plot, diameter umbi, dan panjang umbi. Nilai tengah bobot basah umbi per tanaman genotipe BP-01, BP02, BP-25, dan BP-60 berturut-turut adalah $2.01 \mathrm{~g}, 3.01$ g, $5.51 \mathrm{~g}$, dan $5.63 \mathrm{~g}$, sedangkan nilai tengah bobot kering umbi per tanaman keempat genotipe tersebut berturut- turut adalah $1.54 \mathrm{~g}, 1.99 \mathrm{~g}, 4.35 \mathrm{~g}$, dan $3.26 \mathrm{~g}$. Pengukuran bobot basah dilakukan setelah umbi bawang putih dipanen, sedangkan pengukuran bobot kering dilakukan setelah umbi dikeringkan selama 14 hari. Nilai bobot kering umbi per tanaman lebih rendah dibandingkan bobot basah umbi per tanaman. Hal tersebut menunjukkan adanya penyusutan bobot akibat proses pengeringan. Bobot kering umbi per plot BP-01, BP-02, BP-25, dan BP-60 berturut-turut adalah 15.69 g, 24.23 g, 32.28 g, dan 10.36 g. Jumlah siung genotipe bawang putih yang diuji berkisar antara 1-7 siung per umbi. BP-60 mempunyai jumlah siung yang paling sedikit dibandingkan genotipe lain, yakni rata-rata 1 siung per umbi (umbi tunggal). Brewster (2008) menjelaskan bahwa pembentukan umbi tunggal disebabkan oleh proses vernalisasi yang terlalu lama sehingga umbi terbentuk terlalu cepat, sebelum pembentukan cabang aksilar. Bawang putih introduksi mempunyai nilai tengah bobot kering siung per umbi dan panjang siung yang lebih tinggi dibandingkan bawang putih lokal. Nilai lebar siung tertinggi dimiliki oleh genotipe BP-60.

Bawang putih introduksi secara umum mempunyai pertumbuhan yang lebih baik daripada bawang putih lokal, tetapi kemampuannya untuk menghasilkan umbi justru lebih rendah. Brewster (2008) menjelaskan bahwa proses pengumbian dipicu oleh panjang hari, suhu, serta rasio cahaya merah pendek dan panjang. Penyimpanan bahan tanaman pada suhu $2{ }^{0} \mathrm{C}-4{ }^{\circ} \mathrm{C}$ dapat memicu pengumbian pada bawang putih, sedangkan suhu yang lebih rendah (-2 ${ }^{0} \mathrm{C}$ sampai $2{ }^{\circ} \mathrm{C}$ ) dapat menginisiasi pembentukan bunga.

Hasil penelitian Wu et al. (2016) menunjukkan bahwa suhu tinggi dan hari panjang mampu meningkatkan proses pembentukan umbi dengan periode tumbuh yang lebih singkat dan bobot umbi yang lebih tinggi. Tiga kultivar bawang putih yang diuji menghasilkan umbi dengan bobot yang lebih tinggi pada suhu $20{ }^{\circ} \mathrm{C}$ atau $25{ }^{\circ} \mathrm{C}$ dengan panjang hari 14 jam.

Lokasi penelitian ini memiliki suhu rata-rata harian sebesar $26{ }^{\circ} \mathrm{C}$ dengan rata-rata lama penyinaran 6.12 jam (BMKG, 2018). Panjang hari tersebut belum memenuhi kebutuhan tanaman bawang putih untuk melakukan proses pengumbian. Meski demikian, empat genotipe bawang putih

Tabel 5. Nilai tengah karakter vegetatif tujuh genotipe bawang putih pada 6 MST

\begin{tabular}{cccccc}
\hline Genotipe & Tinggi tanaman $(\mathrm{cm})$ & Panjang daun $(\mathrm{cm})$ & Lebar daun $(\mathrm{cm})$ & Jumlah daun & $\begin{array}{c}\text { Diameter batang } \\
\text { semu }(\mathrm{mm})\end{array}$ \\
\hline BP-01 & $21.65 \mathrm{bc}$ & $17.48 \mathrm{bc}$ & $0.53 \mathrm{bc}$ & $3.0 \mathrm{~b}$ & $3.1 \mathrm{bc}$ \\
BP-02 & $10.49 \mathrm{c}$ & $8.54 \mathrm{c}$ & $0.49 \mathrm{c}$ & $1.3 \mathrm{c}$ & $2.4 \mathrm{c}$ \\
BP-25 & $34.30 \mathrm{ab}$ & $31.05 \mathrm{ab}$ & $0.82 \mathrm{~b}$ & $4.0 \mathrm{ab}$ & $4.4 \mathrm{~b}$ \\
BP-33 & $47.97 \mathrm{a}$ & $42.88 \mathrm{a}$ & $1.28 \mathrm{a}$ & $5.3 \mathrm{a}$ & $7.5 \mathrm{a}$ \\
BP-35 & $50.98 \mathrm{a}$ & $46.06 \mathrm{a}$ & $1.42 \mathrm{a}$ & $5.0 \mathrm{a}$ & $7.7 \mathrm{a}$ \\
BP-60 & $49.62 \mathrm{a}$ & $44.59 \mathrm{a}$ & $1.33 \mathrm{a}$ & $5.3 \mathrm{a}$ & $7.6 \mathrm{a}$ \\
BP-100 & $47.92 \mathrm{a}$ & $44.25 \mathrm{a}$ & $1.30 \mathrm{a}$ & $5.3 \mathrm{a}$ & $7.7 \mathrm{a}$ \\
\hline
\end{tabular}

Keterangan: Angka-angka yang diikuti huruf yang sama pada kolom yang sama menunjukkan tidak berbeda nyata berdasarkan uji lanjut Beda Nyata Jujur (BNJ) pada taraf $\alpha=5 \%$ 
Tabel 6. Nilai tengah komponen hasil 7 genotipe bawang putih

\begin{tabular}{cccccccccc}
\hline Genotipe $\begin{array}{c}\text { Bobot basah Bobot kering Bobot kering } \\
\text { umbi/ } \\
\text { tanaman }(\mathrm{g})^{\mathrm{t}}\end{array} \begin{array}{c}\text { umbi/ } \\
\text { tanaman }(\mathrm{g})^{\mathrm{t}}\end{array}$ & $\begin{array}{c}\text { umbi/plot } \\
(\mathrm{g})^{\mathrm{t}}\end{array}$ & $\begin{array}{c}\text { Diamer } \\
\text { umbi }(\mathrm{cm})\end{array}$ & $\begin{array}{c}\text { Panjang } \\
\text { umbi }(\mathrm{cm})\end{array}$ & \multicolumn{3}{c}{$\begin{array}{c}\text { Jumlah } \\
\text { siung/ umbi }\end{array}$} & $\begin{array}{c}\text { Bobot kering } \\
\text { siung/ umbi } \\
(\mathrm{g})\end{array}$ & $\begin{array}{c}\text { Lebar siung Panjang } \\
(\mathrm{cm})\end{array}$ & siung $(\mathrm{cm})$ \\
\hline $\mathrm{BP}-01$ & $2.01 \mathrm{a}$ & $1.54 \mathrm{a}$ & $15.69 \mathrm{a}$ & $1.36 \mathrm{a}$ & $1.67 \mathrm{a}$ & $2.3 \mathrm{a}$ & $0.69 \mathrm{~b}$ & $0.93 \mathrm{c}$ & $1.25 \mathrm{~b}$ \\
$\mathrm{BP}-02$ & $3.01 \mathrm{a}$ & $1.99 \mathrm{a}$ & $24.23 \mathrm{a}$ & $1.61 \mathrm{a}$ & $2.06 \mathrm{a}$ & $2.3 \mathrm{a}$ & $0.69 \mathrm{~b}$ & $1.07 \mathrm{bc}$ & $1.49 \mathrm{~b}$ \\
$\mathrm{BP}-25$ & $5.51 \mathrm{a}$ & $4.35 \mathrm{a}$ & $32.28 \mathrm{a}$ & $2.22 \mathrm{a}$ & $2.51 \mathrm{a}$ & $2.6 \mathrm{a}$ & $1.92 \mathrm{a}$ & $1.54 \mathrm{ab}$ & $1.99 \mathrm{a}$ \\
$\mathrm{BP}-60$ & $5.63 \mathrm{a}$ & $3.26 \mathrm{a}$ & $10.36 \mathrm{a}$ & $1.77 \mathrm{a}$ & $2.51 \mathrm{a}$ & $1.0 \mathrm{~b}$ & $2.76 \mathrm{a}$ & $1.76 \mathrm{a}$ & $2.46 \mathrm{a}$ \\
\hline
\end{tabular}

Keterangan: $\quad$ t: transformasi data $=\log (10 \mathrm{x})$. Angka-angka yang diikuti huruf yang sama pada kolom yang sama menunjukkan tidak berbeda nyata berdasarkan uji lanjut Beda Nyata Jujur (BNJ)

yang diuji terbukti mampu berumbi pada semua ulangan. Hal tersebut menunjukkan bahwa keempat genotipe yakni BP-01, BP-02, BP-25, dan BP-60 mampu beradaptasi pada kondisi lingkungan dengan panjang hari yang relatif pendek.

\section{KESIMPULAN}

Empat genotipe bawang putih introduksi dari Cina (BP-33, BP-35, BP-60, dan BP-100) mempunyai pertumbuhan vegetatif yang lebih baik dibandingkan bawang putih lokal (BP-01 dan BP-02). Pertumbuhan vegetatif BP-25 tidak berbeda nyata dengan BP-01. Pertumbuhan vegetatif kedua genotipe lokal tidak berbeda kecuali pada karakter jumlah daun. Genotipe BP-01 mempunyai jumlah daun yang lebih banyak daripada BP-02.

Bawang putih yang cocok dikembangkan di dataran rendah Indonesia secara umum adalah bawang putih tipe hardneck, seperti genotipe BP-01, BP-02, dan BP-25. Genotipe BP-60 merupakan bawang putih tipe softneck yang berpotensi dikembangkan di dataran rendah. Baik bawang putih lokal maupun introduksi yang mampu berumbi di dataran rendah mempunyai bobot per plot yang tidak berbeda nyata. Genotipe BP-60 mempunyai jumlah siung per umbi yang paling sedikit di antara genotipe lain. Kedua genotipe bawang putih introduksi (BP-25 dan BP60) mempunyai nilai tengah bobot kering siung per umbi dan panjang siung yang lebih tinggi dibandingkan genotipe bawang putih lokal.

\section{DAFTAR PUSTAKA}

[BMKG] Badan Meteorologi Klimatologi dan Geofisika. 2018. Data Iklim September 2017-Maret 2018. Stasiun Klimatologi Bogor dan Pos Hujan Cibalagung, Bogor, ID.

[BPS dan Ditjen Horti] Badan Pusat Statistik dan Direktorat Jenderal Hortikultura. 2017. Luas panen bawang putih menurut provinsi, 2012 - 2016.http://www.pertanian. go.id/Data5tahun/HortiATAP2016/L.\%20Panen \%20 Bawang\%20Putih. pdf [6 Desember 2017].
[BPS dan Ditjen Horti] Badan Pusat Statistik dan Direktorat Jenderal Hortikultura. 2017. Produktivitas bawang putih menurut provinsi, 2012 - 2016.http://www. pertanian.go.id/Data5tahun/HortiATAP2016/ Produktivitas\%20Bawang\%20Putih. pdf [6 Desember 2017].

[BPS] Badan Pusat Statistik. 2016. Konsumsi per kapita dalam rumah tangga menurut hasil Susenas. http:// www.aplikasi2. pertanian.go.id/konsumsi// tampil_ susenas_kom2_th.php [6 Desember 2017].

[BPS] Badan Pusat Statistik. 2016. Statistik Tanaman Sayuran dan Buah-buahan Semusim. Badan Pusat Statistik, Jakarta, ID.

[FAO] Food Agriculture Organization. 2017. Production/ yield quantities of garlic in Cina, mainland 2010 - 2014.http://www.fao.org/faostat/en/\#data/ QC/ visualize [4 Desember 2017].

[Kementan] Kementerian Pertanian. 2017. Introduksi komoditi pertanian berdasarkan negara asal subsektor hortikultura (segar) periode Januari-September 2017. http://www.aplikasi.pertanian.go.id/eksim2012/ hasilintroduksiNegara.asp. [6 Desember 2017].

Brewster, J.L. 2008. Onion and Other Vegetable Alliums 2nd Edition (Crop Production Science in Horticulture Series 15). CAB International, Wallingford.

Hardiyanto, N.F., Devy, A. Supriyanto. 2007. Eksplorasi, karakterisasi, dan evaluasi beberapa klon bawang putih lokal. J. Hort 17 (4): 307-313.

Hilman, Y., A. Hidayat, Suwandi. 1997. Budidaya Bawang Putih di Dataran Tinggi. Balai Penelitian Tanaman Sayuran, Bandung.

Jenkins, R., C.K. Jain. 2010. Advances in Soil-borne Plant Diseases. Oxford Book Company, Jaipur. 
Menteri Pertanian. 1984. Deskripsi Bawang Putih Varietas Lumbu Hijau. http://varitas.net/dbvarietas/ deskripsi/2027. pdf. [21 April 2018].

Rubatzky, V.E., M. Yamaguchi. 1998. Sayuran Dunia: Prinsip, Produksi, dan Gizi, Jilid 2. Penerbit ITB, Bandung.

Sari W.P., Damanhuri dan Respatijarti. 2014. Keragaman dan heritabilitas 10 genotip pada cabai besar (Capsicum annuum L.). Jurnal Produksi Tanaman 4(2):301-307.

Setiawati, W., R. Murtiningsih., G.A. Sopha, T. Handayani. 2007. Petunjuk Teknis Budidaya Sayuran. Balai Penelitian Tanaman Sayuran, Bandung.
UPOV. 2001. Guidelines for the conduct of tests for distinctness, uniformity, and stability of garlic (Allium sativum L.). International Union for The Protection of New Varieties of Plants, Geneva.

Walker, J.C. 1957. Plant Pathology Second Edition. McGraw-Hill Book Company, Inc., New York.

Wu, C., M. Wang, Z. Cheng, H. Meng. 2016. Response of garlic (Allium sativum L.) bolting and bulbing to temperature and photoperiod treatments. Biologi Open 5:507-518. 